\title{
[IN]SUSTENTABILIDADE, DESENVOLVIMENTO E SEGURANÇA ALIMENTAR
}

\author{
Daiane Loreto de Vargas ${ }^{1}$ \\ Silvia Naiara Borba ${ }^{2}$ \\ Cristiane Maria Tonneto Godoy ${ }^{3}$
}

\section{Resumo}

O termo desenvolvimento sustentável surgiu como uma proposta de mudança de paradigma, quanto à forma de viver da sociedade moderna. Tendo em vista que a padronização da vida social e das formas de consumo passou a ser idealizada por uma questão estritamente econômica. Fato que tem sido motivo de criticas e de vários estudos acadêmicos, onde se analisa o cenário de insustentabilidade socioambiental que tem sido gerado, o qual tem influenciado na questão da segurança e da soberania alimentar dos povos. Este trabalho tem por finalidade debater com base teórica e crítica a necessidade de abranger um padrão mais elevado na escala do desenvolvimento sustentável, retratando quais os desafios da segurança e da soberania alimentar no Brasil, metodologicamente faz-se um resgate bibliográfico explorando o tema proposto.

Palavras-chaves: segurança alimentar, socioambiental, desenvolvimento sustentável.

\section{INTRODUÇÃO}

A palavra desenvolvimento, que antes era sinônimo de progresso e crescimento, hoje passa por outro enfoque, o da sustentabilidade. Para que se alcance a sustentabilidade é preciso que uma série de indicadores econômicos, culturais, políticos, tecnológicos, ambientais, éticos e sociais atuem de forma integrada. Alguns autores tem se dedicado a essa discussão: Goodland (1997), Guzmán (2009), Ruscheinsky (2004), Caporal e Costabeber (2007), entre outros.

O novo paradigma surge de uma necessidade socioambiental, pois o modelo econômico vigente estava degradando tanto o meio ambiente, quanto a sociedade como um todo, transformando o mundo em um lugar insustentável. A menos de 60 anos tomávamos como base para o desenvolvimento somente os aspectos econômicos, o que acarretou em extrema competitividade e desgaste dos recursos naturais pelo atual modelo convencional proposto para a agricultura. $\mathrm{O}$ mercado tomou um rumo extremamente individualista e transformou a racionalidade da sociedade, onde o atual padrão de vida e de consumo social não se sustenta.

\footnotetext{
${ }^{1}$ Tecnóloga em Agropecuária (UERGS), Mestre e Doutoranda em Extensão Rural (UFSM). E-mail: loretodevargas@gmail.com

${ }^{2}$ Graduanda do Curso de Zootecnia (UFSM). E-mail: naiara_seb@yahoo.com.br

3 Engenheira Agrônoma (UFSM), Mestre e Doutoranda em Extensão Rural (UFSM). E-mail: guriaccr@hotmail.com
} 

A perspectiva desenvolvimentista, notoriamente hegemônica no período pós Segunda Guerra, orientava para o crescimento econômico, permanente e baseado no consumo abusivo de recursos naturais não renováveis, como condição básica e indispensável para que as sociedades tidas como subdesenvolvidas superassem o 'atraso' e alcançassem o 'progresso', condição já presente nas nações e sociedades consideradas como desenvolvidas. Os problemas gerados nesse processo e as insuficiências desse enfoque já são bastante conhecidos [...] o reconhecimento da crescente insustentabilidade do modelo convencional de desenvolvimento resultou de uma série de eventos [...] que ao longo dos últimos 40 anos, vem despertando a comunidade científica e a opinião pública sobre a necessidade de novos enfoques, mais respeitosos com o meio ambiente, socialmente desejáveis, politicamente aceitáveis e viáveis sob o ponto de vista econômico.

Em contrapartida a esse cenário que estuda, conceitua pesquisa e desenvolve metodologias para que o novo paradigma chegue a realidades de todos os recantos, o agronegócio se apresenta, relatando o Brasil, com números expressivos que mascaram a realidade do país, em função da desigualdade social e da "in" segurança alimentar pela qual passa a sociedade brasileira.

\section{REALIDADE INSUSTENTÁVEL}

Embora o Brasil seja considerado o celeiro do mundo, os crescentes preços dos alimentos tem oprimido os consumidores das classes menos favorecidas, contribuindo para o aumento das desigualdades sociais em todas as regiões dos pais, os principais produtos produzidos aqui são para o abastecimento externo. A inflação, as altas taxas de juros, impostos e a degradação ambiental causada pela maximização da economia com pacotes tecnológicos importados de outros países, com objetivos de incentivar as cadeias do agronegócio a qualquer preço.

O Brasil esta perdendo a valiosa biodiversidade de seus ecossistemas naturais: Mata Atlântica, Cerrado, Pampa e Pantanal estão ameaçados. Estudos alertam que o Pantanal está correndo sérios riscos de desaparecer numa média de 45 anos, se continuar a ser devastado a uma percentagem de 2,3\% ao ano, a situação é ainda pior se forem avaliados os dados referentes a Mata Atlântica, de toda a Mata existente na época do descobrimento do Brasil restam somente $8 \%$, já o Cerrado possui somente $22 \%$ do seu ecossistema original (WEISSHEIMER, 2006). 
A grande e valiosa biodiversidade do Brasil passa por um processo de padronização, em função da entrada da produção de commodities no país e a perda do conhecimento do produtor, quanto às formas de manejo sustentáveis que preservam seu ecossistema natural. Ou seja, o ingresso do agronegócio aliado ao poder capitalista, que juntos transforma nossa agricultura em comércio, exportação, destruição ambiental, esta contribuindo para a perda do "saber fazer" do produtor rural e gerando uma erosão sócio-cultural na sociedade (JUNGES, 2008).

A busca da modernização do campo sem precedentes está gerando uma alta nos preços dos alimentos, excluindo ainda mais as camadas mais pobres da população, o agronegócio ocupa uma grande área de terras no Brasil, sendo que $43 \%$ do total dessas terras são ocupadas pela soja e pela pecuária extensiva, outra monocultura em expansão é a cana-de-açúcar utilizada, na maior parte, para a exportação de etanol (BENAYON, 2008). O principal produto da soja é o farelo de soja, com objetivo de formular rações para a alimentação de animais no exterior, a pecuária também gera produtos de exportação, carnes para a mesa da classe média e alta dos países importadores.

Por outro lado, a situação ambiental se deteriorou, no último quarto de século surgiram 13 novas doenças infecciosas, decorrentes de desequilíbrios ambientais, com um custo estimado de 550 bilhões de dólares para a saúde pública. Os níveis médios da sociedade ganharam $10 \%$ de riqueza em relação aos pobres, enquanto que os mais ricos ganharam 23\% em relação aos setores médios (WEISSHEIMER, 2006).

Nesse sentido, Leite e Pietraffesa (2003) relatam que é comum a desnutrição em pessoas que possuem suas necessidades energéticas, alimentares, corretamente atendidas, gerando quadros de enfermidades no futuro, devido à inadequada dieta. Os mesmos autores descrevem que a fome no Brasil não é em função de falta de alimentos e sim em função da desregular distribuição de renda, gerando uma falta de poder aquisitivo e de acesso aos meios de produção.

Essa economia está gerando que tipo de sociedade? Uma das recomendações aprovadas por 170 chefes de Estado, durante a Conferência da ONU sobre Meio Ambiente e Desenvolvimento (Rio 92), defendeu a necessidade de adoção de sistemas de contabilidade nacional mais abrangente, incluindo critérios sociais e ambientais, e não apenas monetários. Mas, a contabilidade suicida dos economistas segue dando às cartas, enquanto assistimos todos os dias na televisão, meio atordoados, a contínua destruição das principais riquezas naturais do país e do planeta (WEISSHEIMER, 2006, p. 5). 
Para construir um processo mais igualitário é necessário que haja programas que promovam a igualdade do setor produtivo, sem afetar a capacidade de regeneração do sistema. Para tanto, atingir o desenvolvimento rural não é apenas resolver os aspectos ambientais pertinentes a questão, mas também fortalecer a idéia da equidade social. Nesse sentido, os programas de desenvolvimento rural fortalecem:

Las propuestas nuevas de desarrollo rural están centradas mas bien en la promoción de instituciones y organizaciones locales capaces de responder a las demandas de los campesinos y pequeños productores. Dichas propuestas buscan movilizar los recursos locales, humanos, económicos y de conocimiento, existentes en las comunidades y darles una forma organizativa particular, que permita responder a las demandas para las cuales los campesinos tienen una demanda efectiva y están dispuestos a contribuir a ellos. Parte de la idea que si dichos servicios les entregan apoyos que tienen um resultado efectivo, en forma de mejoras de ingresos, los campesinos estarán dispuestos a pagar por ello. En buena parte de casos las organizaciones locales están en capacidad de entregar esos servicios a costos más bajos que las similares, publicas o privadas, pues tienen costos de transacción inferiores. Dichas organizaciones deben lograr un buen arreglo entre la tecnología que busca ofertar y la organización, en términos de gestión, secuencias de expansión incentivos, etc. Al mismo tiempo debe ser eficientes y efectivas (CHIRIBOGA, 1999, p. 6).

\section{AGROECOSSITEMAS SUSTENTÁVEIS: UMA NECESSIDADE FRENTE A ATUAL INSUSTENTABILIDADE SOCIOAMBIENTAL}

A utilização da ciência e de novas tecnologias impôs um novo manejo dos recursos naturais, substituindo o conhecimento local, com isso a natureza passou a ser dominada pelo homem, o qual visando o lucro e a conquista de mercados começou a substituir o manejo dos recursos naturais e a produção de base ecológica pelos processos biológicos (GUZMÀN, 2009).

A economia humana utiliza atualmente $40 \%$ da produção primária de fotossíntese terrestre, provocando erosão do solo, contaminação dos rios, desigualdade social e ambiental. Além do aquecimento global, a temperatura média está aumentando em função do alto consumo de dióxido de carbono liberado pelo petróleo e pelo gás natural, ocasionando danos a agricultura e a intensidade de fenômenos naturais que antes eram raros (GOODLAND, 1997). 
III SEMINÁRII ECOLOGIA

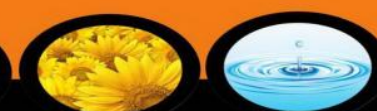

PDLÍTICA

A atividade humana contribui para a degradação da camada de ozônio, aumentando a radiação ultravioleta, o câncer de pele e a redução da eficácia do sistema imunológico, dentre outras anormalidades. Outra consequência visível é a degradação ambiental, a qual tem ocasionado perda de produtividade das culturas, salinização, desertificação e erosão do solo. Temos atualmente $35 \%$ do solo terrestre degradado (GOODLAND, 1997).

Quanto à biodiversidade, está ocorrendo extinção de espécies, desaparece anualmente em torno de 5.000 espécies, a causa é a invasão do seu habitat natural. No passado esses dados eram bem diferentes, pois, o subsistema econômico era reduzido em relação ao ecossistema global, o inverso do que presenciamos hoje (GUZMÁN, 2009).

Limites localizados e limite global, os subsistemas econômicos ultrapassam os limites e a capacidade de receber resíduos humanos, que aumentam cada vez mais e são jogados nas águas dos oceanos (GOODLAND, 1997). A modernização e a globalização impuseram seu conceito de padrão de vida ditado pelos países industrializados, que também impuseram o conceito de subdesenvolvimento e de desenvolvimento.

Diante do cenário de insustentabilidade socioambiental, nasce a nível mundial um consenso pela necessidade de novas estratégias, que contribuam para a construção de agroecossistemas sustentáveis, visando a segurança na produção de alimentos e a preservação ambiental (ALTIERI E NICHOLLS, 2000).

\section{NECESSIDADE DA SEGURANÇA E DA SOBERANIA ALIMENTAR}

Diante da fome e da miséria dos países subdesenvolvidos, surge a soberania alimentar que se define por:

\footnotetext{
"Soberania alimentar é o direito dos indivíduos, das comunidades, dos povos e dos países de definir as políticas próprias da agricultura, do trabalho, da pesca, do alimento e da terra. São políticas públicas ecológicas, sociais, econômicas e culturais, adaptadas ao contexto único de cada país. Inclui o direito real ao alimento e à produção do alimento, o que significa que todo mundo tem o direito ao alimento seguro, nutritivo e adaptado à sua cultura e aos recursos para produção de comida; à possibilidade de sustentar-se e sustentar as suas sociedades".
} 
Esses conceitos começam a ser discutidos na Primeira Conferência de Desenvolvimento Rural Sustentável e Solidário, este foi um espaço público de construção de políticas voltadas para a agricultura familiar, o qual se converteu num interessante laboratório para a análise desse novo formato de "fazer" política pública nacional (KISCHENER, 2004).

Foram discutidos assuntos relevantes como: prioridade da produção agrícola local para alimentar a população local (o saber fazer local); acesso da agricultura familiar, dos povos que vivem da pesca e dos sem-terras a terra, água, sementes, matrizes de gado, e crédito, incentivo a diversificação da produção, reforma agrária e a luta contra os transgênicos.

Reivindicando o direito da população ao direito ao alimento, o direito dos agricultores familiares de produzir alimentos e o reconhecimento dos direitos dos agricultores, o direito dos consumidores de decidir sobre o que consumir, como e por quem é produzido, o direito dos países de defender-se contra uma agricultura que pratica preços abaixo do custo de produção e contra a importação dos alimentos, a necessidade dos preços terem relação com os custos da produção, a participação da população, incentivos a agroecologia.

A Soberania Alimentar pretende construir um novo paradigma agroalimentar baseado na implementação do direito à alimentação, no acesso dos camponeses aos recursos, numa produção sustentável e na prioridade aos mercados e circuitos de comercialização locais. Propõe resolver o problema da escassez de alimentos. É uma ferramenta metodológica para analisar e compreender vários fenômenos complexos e uma estratégia para abordar os problemas da agricultura mundial e da fome no início do séc. XXI (GUIMARÃES, 2008, p.4)

Este é um direito da população que hoje com várias doenças, inclusive psíquicas devido a falta de qualidade nutricional dos alimentos. Essa realidade pode ser revertida com as iniciativas do desenvolvimento sustentável como a valorização do saber fazer cultural da população rural, a valorização da agricultura familiar e a diversificação das propriedades rurais, respeitando a identidade local e também através dos instrumentos como as políticas públicas, a legislação que deve na prática proteger o meio ambiente.

A modernização da agricultura, nas últimas décadas, tem provocado muitas mudanças no cenário social, refletindo inclusive na [in] segurança alimentar dos 
próprios agricultores. Isto porque neste modelo de produção [excludente] que acabou integrando a agricultura familiar às grandes cadeias mercantis, priorizando as “commodities" para o mercado mundial, desvalorizou a produção de alimentos para o consumo das famílias agricultoras (REDIN et al, 2009).

Pode-se argumentar que, nesse contexto, induzidos pelas políticas de crédito rural para as atividades de grande escala, a agricultura familiar necessitou abandonar os cultivos de subsistência para adequar-se a lógica capitalista. Em busca de maior lucratividade por hectare, muitas vezes, abandona-se a agricultura diversificada e assume-se a especialização em um, ou no máximo dois, produtos de apelo de mercado.

Esse reflexo evidente, da especialização perante a lógica produtiva empresarial, em que está modificando a racionalidade da agricultura familiar afeta diretamente a segurança alimentar seja dos próprios agricultores, que não plantam mais o alimento e tendem a ir aos centros urbanos adquirir, com a renda gerada na agricultura, o alimento. Ou ainda, pelo fato da importante contribuição da agricultura familiar na produção de alimentos no Brasil, que está em torno de $75 \%$ da produção total. Ao abandonar essa prática, todo um sistema dependente dessa classe é afetado provocando influencia nas suas práticas alimentares, bem como possivelmente na sua dieta.

Esse processo de simplificação da dieta pelo abandono da produção para subsistência gera o que Balem e Silveira (2005) denominam de erosão cultural alimentar, definida como a perda gradativa de uma alimentação variada, mais complexa nutricionalmente, alicerçada na cultura do agro e adoção de práticas e hábitos alimentares urbanos.

De acordo com os autores, esse processo tem levado a uma situação de não soberania alimentar dos agricultores, pois a família não é mais o destino das atividades agrícolas, muito menos tem poder de decisão de como plantar, pois tudo já está definido dentro do pacote tecnológico e mercadológico do qual estão inseridos. Sendo assim, não são mais capazes de atender as necessidades alimentares de sua família, dependendo de uma renda monetária para garanti - lá.

Todo esse contexto, retratado sobre a lógica da agricultura familiar vem em decorrência do alto poder de influência do agronegócio que faz com que a agricultura de pequena propriedade rural estabeleça nesse contexto, mesmo muitas vezes sendo 



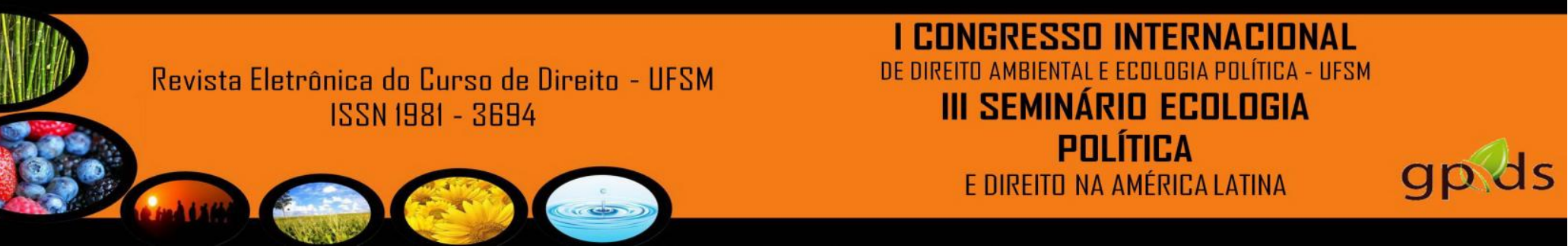

Por este contexto é interessante o meio acadêmico levar ao conhecimento da sociedade em geral os vários desafios, em termos de segurança e da soberania alimentar frente ao poder do agronegócio brasileiro, principalmente em sinal de alerta a população quanto à mudança que o homem esta sofrendo com várias novas doenças surgindo, desequilíbrio nutricional e muito mais em função dessa erosão alimentar que nós estamos condicionados pelo poder do capital.

Por fim, e com base no pensamento de Junges (2006), reiteramos que o maior dever ético da sociedade é por "motivos éticos e patrimoniais". Os seres humanos têm por dever não eliminar outras formas de vida, deixando que às gerações futuras tenham o direito de desfrutar dos ecossistemas naturais, já que estes são classificados pelo autor como "laboratórios" para a compreensão da evolução e da sobrevivência da humanidade.

Coloca-se, como pressuposto básico, para atingirmos um padrão superior na escala do desenvolvimento sustentável, a suavização dos impactos que a população tem sofrido no que tange ao seu padrão de consumo alimentar. A importância dos instrumentos para a realização do desenvolvimento sustentável, tais como: políticas públicas, legislação com fiscalização e a fundamental atuação dos profissionais das ciências rurais no sentido educativo e conscientizador da população.

\section{REFERÊNCIAS}

AGENDA 21 BRASILEIRA. Bases para a discussão. Washington Novais (Coord.) Otto Ribas e Pedro da Costa Novaes. MMA/PNUD. Brasília, 2000.

ALTIERI, M; NICHOLLS, C, I. Agroecología: teoría y práctica para uma agricultura sustentable. Série Textos Básicos para la Formación Ambiental. $1^{\text {a }}$ Edición. México: PNUMA, 2000, p.250.

BALEM, T.; SILVEIRA, P. R. C. A Erosão Cultural Alimentar: processo de insegurança alimentar na agricultura familiar. In: Congresso da Associação LatinoAmericana de Sociologia Rural, Anais. 2005. Disponível em: <www.ufsm.br/desenvolvimentorural>, Acesso: 10 de ago. de 2012.

BENAYON, A. Alta de preços dos alimentos no Brasil, crônicas e críticas da América Latina - um lugar para o debate honesto, livre e inteligente. 2008. Disponível em: < http://cafenapolitica.blog.br/blog/archives.php?showall=1>. Acesso: 12 de ago. de 2012. 


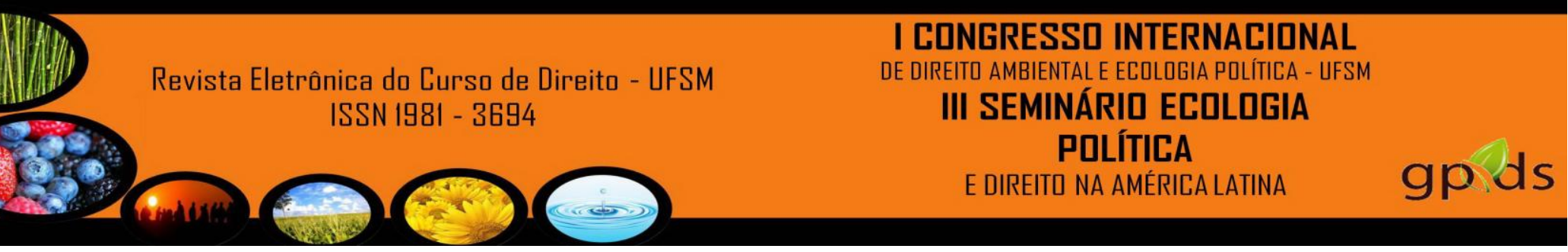

CAPORAL, F. R.; COSTABEBER, J. A. Agroecologia e extensão rural: contribuições para a promoção do desenvolvimento rural sustentável. Brasília: MDA/SAF/DATER. 2007.

CAPORAL, F. R.; COSTABEBER, J. A. Possibilidades e alternativas do desenvolvimento rural sustentável. "I Congresso Internacional sobre Agricultura Familiar e Desenvolvimento Rural Sustentável", Universidade Federal de Santa Maria, Santa Maria, RS/ 2003. p.157-194.

CARVALHO, H. M. IMPACTOS ECONÔMICOS, SOCIAIS E AMBIENTAIS DEVIDO Á EXPANSÃO DA OFERTA DO ETANOL NO BRASIL. CURITIBA, 2007. DISPONÍVEL EM: <WWW.LANDACTION.ORG/SPIP/SPIP.PHP?ARTICLE190 - 90K>. ACESSO EM: 02 DE AGO. DE 2012.

CAVAlCANTI, C. Desenvolvimento e natureza: estudos para uma sociedade sustentável. São Paulo, Cortez Editora, 1995. 429 p.

CHIRIBOGA, M. Que hemos aprendido en desarrollo rural en los 90? IICA, San José, 1999.

GOODLAND, R. La tesis de que el mundo está en sus límites. Medio ambiente y desarrollo sostenible : más allá del informe Brundtland. p. 19 -36, 1997. Disponível em: $\langle$ http://dialnet.unirioja.es/servlet/articulo?codigo=576942>. Acesso: 04 de ago. de 2012.

GUIMARÃES, G. M. Agricultura familiar e sustentabilidade sistematização do seminário: "soberania alimentar e identidade territorial" (mimio), 2008

GUZMÁN, E. S. Agroecología y desarrollo rural sustentable: una propuesta desde latino américa. $2009 . \quad$ Disponível em: <http://geografiaposgrado.files.wordpress.com/2009/04/agroecologiaydesarrollorura1.p df>. Acesso em: 07 de ago. de 2012.

JUNGES, J. R. Bioética e meio ambiente no Brasil: uma abordagem hermenêutica. Escola de formação fé, política e trabalho - Diocese de Caxias do Sul. Disponível em: <www.pastoraldecaxias.org.br/>. Acesso em: Acesso: 07 de ago. de 2012.

LEITE,T. S.; PIETRAFFESA, J. P. Situação da (in)segurança alimentar no Brasil. Revista da Proec: Tema Fome Made In Brazil. Publicação semestral da Pró-Reitoria de Extensão e Cultura da UFG. Ano V, Revista da UFG, Vol. 5, No. 1, abr 2003 on line. Disponível em: 〈www.proec.ufg.br〉. Acesso: 31 de ago. de 2012.

KISCHENER. M. A. (Re) Educar para a vida? Um retorno ao passado? A contribuição da agroecologia na transição para um mundo melhor. 2004. Disponível em: <http://www.acompanhamentoproninc.org.br/producao/artigos/artigo-agroecologia.pdf $>$ Acesso: 02 de ago. de 2012. 


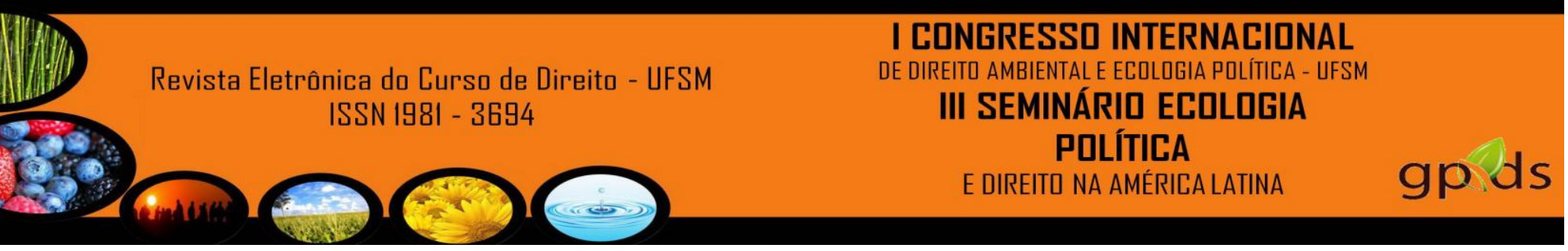

MENDES, M. C. Desenvolvimento Sustentável. Viver Conciente, 2008. Disponível em:

$<$ http://www.viverconsciente.com.br/exibe_artigo.asp?codigo $=76 \&$ codigo_categoria $=9$ $>$. Acesso: 02 de ago. de 2012.

REDIN, E. O desafio da sustentabilidade: o caso das agroindústrias da quarta colônia/RS/Brasil. In: IV Congreso Argentino y Latinoaméricano de Antropologia Rural. Anais... INTA, Mar Del Plata, NADAR, 2009.

REDIN, E. GUIMARAES, G. M., SILVEIRA, P. R. C. A agricultura Familiar e o cultivo do Fumo no Sul do Brasil: um estudo sobre a racionalidade dos atores do município de Arroio do Tigre, RS. In: IV Congresso Argentino y Latinoamericano de Antropologia Rural, 2009, Mar del Plata. Anais... INTA, Mar Del Plata, NADAR, 2009.

REDIN, E.; VARGAS, D. L. O cooperativismo e o desafio de cumprir seus princípios diante de um mundo capitalista e globalizado: o contexto da Coriscal/RS/BRA. In: IV Congreso Argentino y Latinoaméricano de Antropologia Rural. Anais... INTA, Mar Del Plata, NADAR, 2009.

RUSCHEINSKY, Aloísio. Sustentabilidade: uma paixão em Movimento. Porto Alegre: Sulina. 2004.

WEISSHEIMER, M. A. Carta Maior: observatório de políticas públicas ambientais da América Latina e Caribe, GNU/GPL. Disponível em: <http://www.joomla.org/>. Acesso em: 07 de ago. de 2012. 